\title{
Survey of work processes on German dairy farms
}

\author{
A. Hesse, S. Bertulat, and W. Heuwieser ${ }^{1}$ \\ Clinic for Animal Reproduction, Faculty of Veterinary Medicine, Freie Universität Berlin, Königsweg 65, 14163 Berlin, Germany
}

\begin{abstract}
The objective of this study was to conduct a survey to gain insight into the organization of work processes on commercial German dairy farms analyzing the use of standard operating procedures (SOP). Practices and routines were surveyed regarding the existence, creation, and use of SOP. A total of 250 survey forms were returned, and 248 could be used for final analysis. The existence of SOP was indicated by $82 \%$ of all respondents, but only $54 \%$ stated that these SOP were written down. Existence of SOP correlated with farm size such that larger farms were more likely to implement SOP than smaller farms. However, many farmers lacked the time $(41 \%)$ or ability $(42 \%)$ to create SOP to provide the employees with detailed instructions on how to perform a specific task. The majority of respondents $(59 \%)$ were interested in using ready-made SOP that could be adjusted to their farm. An obvious discrepancy exists between the motivation of the farmers to improve the performance on their farm and their expertise in attaining these goals and intentions.
\end{abstract}

Key words: survey, protocol, standard operating procedure, quality management

\section{INTRODUCTION}

Quality assurance programs are designed to help companies improve and maintain process and product quality. Key elements of such programs are protocols and standard operating procedures (SOP). Protocols are company specific and provide information on what to do in certain situations, whereas the SOP within the protocols systematically describe how to do it (Barragan et al., 2016). These SOP define work processes in a detailed and step-by-step manner, providing the employee with clear instructions on how to perform a particular task (Amare, 2012). Consistency of work performance is increased because written instructions manage the variation that arises when individuals

\footnotetext{
Received September 21, 2016.

Accepted April 8, 2017.

${ }^{1}$ Corresponding author: w.heuwieser@fu-berlin.de
}

perform tasks in different ways (Stup et al., 2006). Consequently, fluctuations in product quality are reduced. Regular performance reviews and assessment of the compliance with a given SOP can ensure a high quality of work performance and productivity (Stup et al., 2006).

There exist different quality assurance programs (e.g., Total Quality Management, Six Sigma, Hazard Analysis Critical Control Points) as well as a management system standard of the International Organization for Standardization. The aim of these programs is to establish and implement standards of frequently performed work processes that are consistently reviewed (Manghani, 2011).

Quality assurance programs for industrial manufacturing were introduced a long time ago ( $\mathrm{Yu}$ et al., 1999); however, such concepts are only starting to be developed in human medicine. Recently, SOP have been established for the improvement of cancer diagnostics (Keswani et al., 2015), for the treatment of intensive care patients (Friesecke et al., 2014), for orthopedics and trauma surgery (Ewerbeck, 2014), and for reducing the dose of pediatric X-rays (Kloth et al., 2016). The application-based SOP management program SOPHIA (SOPHIA, 2014) was designed particularly for hospitals to generate and manage SOP and make them available on mobile devices. The developers wanted to ensure the creation of SOP that are widely accepted and always up to date (Bauer et al., 2015). In human medicine, SOP implementation becomes highly important to ensure safety in the practice of medicine and pharmaceutical care (Amare, 2012). Many hospitals, however, still lack the awareness and conditions of strictly performed quality management (Ewerbeck, 2014). This likely applies even more to agriculture and veterinary medicine, even though farmers and veterinarians have major responsibilities in the food chain (Windhaus et al., 2007).

Critical issues such as animal welfare and agricultural sustainability (von Keyserlingk and Hotzel, 2015; German et al., 2016), animal health (Almeida et al., 2015), and the use of critically perceived drugs such as hormones and antibiotics (Bánáti, 2014; Pieper et al., 2016) are increasingly being discussed among the general public. Therefore, control, consistency, and 
transparency of production processes are important to ensuring consumers' trust (McCrea, 2005) and satisfying their needs and expectations (Manghani, 2011). On the other side, dairy farm managers, herdsmen, and workers can benefit from SOP because they provide direction and improve communication and work consistency (Streyl et al., 2011), which lead to predictable results and increase workers' confidence (Stup, 2001; Erskine et al., 2015). Furthermore, the agricultural sector is observing a trend toward larger farms (Moore et al., 2016) with more animals and consequently a higher percentage of nonfamily labor (Bewley et al., 2001; Reynolds et al., 2013; Barkema et al., 2015). In this context, challenges on large dairy farms are caused by communication difficulties, particularly with foreign workers (Stup et al., 2006), and insufficient training of the workforce (Barkema et al., 2015). Those farms could benefit from the implementation of SOP (Cummins et al., 2016), which can help standardize work processes and minimize errors that occur as a result of misinterpretation or miscommunication (Amare, 2012). Thus, fluctuations in product and work quality can be reduced and labor efficiency can be increased.

Currently, little information is available about the utilization of SOP and challenges related to training the workforce on commercial dairy farms. Therefore, the objective of this study was to gain insight into the organization of work processes and to analyze the current use, development, and utilization of SOP and related challenges on German commercial dairy farms.

\section{MATERIALS AND METHODS}

A comprehensive questionnaire was developed that consisted of 16 questions and 9 statements focusing on general farm data; the generation, implementation, and handling of SOP; and assessment of challenges in handling work processes on the farm (Supplemental Figure S1; https://doi.org/10.3168/jds.2016-12029). The questionnaire was distributed in different ways using 3 convenience samples. The first sample included farmers who attended different continuing education events during the third and fourth quarters of 2015 . Approximately 100 farmers attended each of the 3 continuing education events. For the second sample, the survey form was sent by mail to farms mainly in the eastern, northern, and southern regions of Germany. Farms were contacted via mail in cooperation with 2 German breeding organizations (Rinderallianz $\mathrm{GmbH}$, Woldegk, Germany; Rinderunion Baden-Württemberg e.V., Herbertingen, Germany) and a German agricultural publishing company (DLG AgroFood Medien GmbH, Bonn, Germany). Overall, approximately 8,000 farms were contacted. Participation in the survey was voluntary, and the forms were returned anonymously by mail or collected after the education events. The survey form contained a link and a quick response code that offered participants the option to anonymously fill out an online version of the questionnaire developed with the survey software QuestBack (QuestBack GmbH, 2016). Farmers who answered the questionnaire online composed the third sample.

The questionnaire started with a question referring to the types of employment positions. The participant could choose 1 of 4 answers: owner or manager, herdsman, employee, or trainee. The first 6 questions covered general farm information, such as the number of cows, number of employees, annual milk yield, reproductive performance, and bulk milk SCC. Ten questions addressed the development, implementation, and handling of SOP. The last part consisted of 9 statements that participants had to rate on a 5-point Likert scale ranging from fully agree (1) to fully disagree (5).

After the education events, 1 question (question 15) was added to the test instrument. Therefore, the number of questions on the forms differs. The data were entered into Excel spreadsheets (version 2013, Microsoft Inc., Redmond, WA) and statistically analyzed using SPSS Statistics for Windows (version 22.0, IBM Deutschland GmbH, Ehningen, Germany).

Data were screened for plausibility, resulting in the exclusion of implausible answers from the analysis $(\mathrm{n}=$ 1 ). Normality of distributions of continuous parameters was assessed by plotting and visually examining the data, calculating a quantile-quantile plot, and using the Shapiro-Wilk test. Means and corresponding standard deviations as well as the interquartile range (IQR) were computed for continuous and ordinal variables, respectively. The IQR is the difference between the third and first quartiles in a data set and is a measure of how the data spread around the median. Frequencies were calculated for categorical variables. Percentages were rounded to the nearest whole percentage point.

The interrelation between 2 categorical variables was summarized using cross-tabulations, Cramer's V, and Spearman correlation. Binary logistic regression models were calculated to verify the association between various parameters and binary outcome variables. Odds ratios and $95 \%$ CI were estimated to determine the association between different management procedures and opinions of the farmers. Further analyses on continuous variables (i.e., annual milk yield, first-service conception rate, SCC) were carried out applying a linear mixed-model ANOVA. All models were built according to the model-building strategies provided by Dohoo et al. (2009). The effect of individual param- 
Table 1. Questions and statements on the test instrument

\begin{tabular}{|c|c|c|}
\hline No. & Item $^{1}$ & Answered question, \% (no.) \\
\hline & I am owner/manager, herdsman, employee, or trainee. & $98(244 / 248)$ \\
\hline 2 & How many cows calve on your dairy per year? & $98(243 / 248)$ \\
\hline 4 & What was the average bulk tank SCC in the last 3 mo? & $95(236 / 248)$ \\
\hline 5 & What is the average first service conception rate for cows in the last $3 \mathrm{mo}$ ? & $75(185 / 248)$ \\
\hline 6 & How many people (including part-time employees) work in the livestock sector of the farm? & $94(232 / 248)$ \\
\hline 9 & Are these SOP created together with the employees? & $97(241 / 248)$ \\
\hline 10 & Are the employees trained for the use of the SOP? & $96(237 / 248)$ \\
\hline 11 & Do you check the validity of the SOP on a regular basis? & $96(239 / 248)$ \\
\hline 12 & Do the employees have unlimited access to the SOP? & $92(227 / 248)$ \\
\hline 13 & Who helped you create the SOP? & $96(237 / 248)$ \\
\hline 14 & Do you have SOP for your trainees? & $94(234 / 248)$ \\
\hline 15 & Do you see room for improvement for certain areas of your farm? & $98(242 / 248)$ \\
\hline \multicolumn{3}{|c|}{ P } \\
\hline 2 & Sometimes I get annoyed about employees not completing tasks the way I consider right. & $98(243 / 248)$ \\
\hline 3 & In agriculture, we should implement new and scientifically sound findings. & $98(243 / 248)$ \\
\hline 4 & Continuing education for employees is often neglected. & $97(240 / 248)$ \\
\hline 5 & I have been thinking of writing down specific work processes in detail. & $96(239 / 248)$ \\
\hline 6 & I find it difficult to write down work processes. & $97(240 / 248)$ \\
\hline 7 & I do not have the time to create SOP. & $97(241 / 248)$ \\
\hline 8 & I would like to use ready-made SOP and adapt them to my farm. & $97(240 / 248)$ \\
\hline 9 & I would like to use a smartphone or tablet to display such SOP. & $98(243 / 248)$ \\
\hline
\end{tabular}

${ }^{1} \mathrm{SOP}=$ standard operating procedures.

${ }^{2}$ Numbers are lower because this question was added after the first distribution of the questionnaire.

eters and interactions between relevant parameters was checked. Estimated marginal means and corresponding standard error were reported to illustrate the results. The significance level was set at $P \leq 0.05$, and trends were discussed at $0.05<P \leq 0.10$.

Because this study is the first of its kind, reported data for a preceding sample size calculation were not available in the literature. Therefore, a post hoc power analysis was performed using $\mathrm{G}^{*}$ Power (version 3.1.3, University of Düsseldorf, Düsseldorf, Germany) to verify the level of the effect of varying SOP on productions parameters (i.e., milk yield, SCC, first service conception rate). Furthermore, the statistical power of calculations concerning the effect of farm size on the probability of the existence of different SOP was determined. The power of analysis $(1-\beta)$ was calculated, accepting a null hypothesis error of 0.05 .

\section{RESULTS}

A total of 250 questionnaires were returned, and 2 forms were excluded from analysis (1 form was filled out by a beef producer, and 1 form was excluded due to the implausibility of the answers). The majority of the questionnaires (58\%) were collected after the education events mentioned earlier. Another $29 \%$ of participants returned their forms by mail, and $12 \%$ of participants answered their questionnaires online. The questions covering general farm data were answered by $94 \%$ of all participants. A question regarding the benefits of SOP (question 15) was added after the first seminar, leading to only 186 answers out of 248 for that question. The percentage of questions answered ranged from 75 to $98 \%$ (Table 1).

\section{General Farm Data}

The majority of respondents $(64.3 \%)$ were farm managers; $27 \%$ were herdsmen, $7.4 \%$ were employees, and $1.2 \%$ were trainees. The number of cows kept on each farm ranged from 12 to 2,650 , and mean $( \pm \mathrm{SE})$ annual milk yield was $9,611 \pm 74 \mathrm{~kg}$. The annual bulk milk SCC averaged 196,000 $\pm 59,470$ cells $/ \mathrm{mL}$.

Categorizing farms based on cow numbers, $23 \%$ of the farms were small (up to 100 cows; mean $\pm \mathrm{SE}=$ $75.4 \pm 2.7), 52 \%$ were medium (101-500 cows; mean $\pm \mathrm{SE}=265.8 \pm 10.4)$, and $23 \%$ were large $(>500$ cows; mean $\pm \mathrm{SE}=935.9 \pm 55.9$ ), respectively. Five questionnaires did not indicate the number of cows. As expected, the number of employees increased with 
Table 2. First-service conception rate (FSCR) for cows and 305-d milk yield (mean $\pm \mathrm{SE}$ ) for small (0-100 cows), medium (101-500 cows), and large (>500 cows) dairy farms

\begin{tabular}{lrcrr}
\hline & \multicolumn{3}{c}{ Farm size } & \\
\cline { 2 - 4 } Parameter & Small & Medium & Large & $P$-value \\
\cline { 2 - 5 } FSCR & $59 \pm 2.34^{\mathrm{a}}$ & $48 \pm 1.76^{\mathrm{b}}$ & $41 \pm 2.34^{\mathrm{c}}$ & $<0.001$ \\
Milk yield $(\mathrm{kg})$ & $8,960 \pm 140^{\mathrm{a}}$ & $9,759 \pm 96^{\mathrm{b}}$ & $9,994 \pm 148^{\mathrm{b}}$ & $<0.001$ \\
\hline
\end{tabular}

${ }^{\mathrm{a}-\mathrm{c}}$ Within a row, means with different superscripts differ significantly.

the number of cows kept on a farm $(\mathrm{r}=0.896 ; P<$ $0.001)$, with an average of $3.0 \pm 0.8,6.2 \pm 0.6$, and 19.7 \pm 0.8 employees on small, medium, and large farms, respectively $(P<0.001)$. A median of 6 full- or parttime equivalents $($ minimum $=1$; maximum $=68)$ were employed in the milk production sector. On average, each employee (either full or part time) was responsible for $42 \pm 18$ cows.

The median first-service conception rate (FSCR) for cows was 50\% (IQR = 33-60\%); 23, 45, and 32\% of the farms were categorized as having good $(>60 \%)$, moderate $(>40$ to $60 \%)$, and low $(\leq 40 \%)$ reproductive performance, respectively. The FSCR as well as milk yield depended on farm size $(P<0.001)$, such that larger farms had lower FSCR and higher milk yields (Table 2).

\section{SOP}

The majority of all respondents (82\%) indicated the existence of SOP in general. The presence of SOP was significantly influenced by farm size (Table $3 ; P=$ 0.007). Compared with small farms, medium and large farms were $2.11(95 \% \mathrm{CI}=1.04-4.29 ; P=0.039)$ and $5.63(95 \%$ CI $=1.78-17.83 ; P=0.003)$ times more likely to have SOP, respectively.

Standard operating procedures most frequently existed for feeding $(73 \%)$, milking $(73 \%)$, calf handling (64\%), and management of fresh cows (54\%). Medium and large farms were more likely to have SOP for these areas than small farms (Table 4). Interestingly, SCC was significantly higher on farms with an SOP for milking procedures (mean \pm SE: 201,168 $\pm 4,579$ cells $/ \mathrm{mL}$ ) than on farms without an SOP for milking procedures $(181,318 \pm 7.284$ cells $/ \mathrm{mL} ; P=0.023)$.

Annual milk yield, however, was higher on farms where SOP were available in general $(9,690 \pm 176 \mathrm{~kg})$ than on farms without any SOP $(9,286 \pm 82 \mathrm{~kg} ; P=$ 0.038). This was also true for farms that had implemented an SOP for milking procedures (farms with milking SOP, 305d-lactation $=9,730 \mathrm{~kg}$; farms without milking SOP, 305d-lactation $=9,309 \mathrm{~kg} ; P=0.012$ ). In addition, the association between annual milk yield and the existence of a feeding SOP was significant $(P$ $<0.001$ ), with the estimated marginal means showing a higher milk yield when SOP were present (farms with feeding SOP $=9,780 \mathrm{~kg}$; farms without feeding SOP $=9,171 \mathrm{~kg})$. Also, farms that had a milking SOP were 11.00 times more likely to have an SOP for fresh cow management $(95 \% \mathrm{CI}=5.36-22.60 ; P<0.001)$.

The FSCR were lower on farms with an SOP for heat detection $(45.8 \pm 2.1 \%)$ than on farms without an SOP for heat detection $(51.6 \pm 1.6 \%, P=0.026)$. Furthermore, farms with a written SOP for heat detection had lower FSCR $(45.0 \pm 1.8 \%)$ compared with farms that did not put their SOP in writing (52.2 \pm $2.2 \% ; P=0.012$ ).

Farms that had an SOP for calving management were 15.05 times more likely to also have an SOP for managing their fresh cows $(95 \% \mathrm{CI}=7.96-28.48 ; P<$ 0.001). In addition, farms implementing an SOP for feeding were 10.9 times more likely to have an SOP for claw trimming $(95 \% \mathrm{CI}=4.18-28.42 ; P<0.001)$.

Although most respondents $(82 \%)$ indicated the existence of SOP, only $54 \%$ stated that the SOP were available in writing. Whether the SOP were written down depended on farm size $(P=0.002)$ such that medium and large farms were 2.08 times $(95 \% \mathrm{CI}=1.08-4.03$; $P=0.030)$ and 7.24 times $(95 \% \mathrm{CI}=3.21-16.32 ; P<$ $0.001)$ more likely to write down their SOP, respective-

Table 3. Percentage (no.) of respondents to questions related to the existence and implementation of standard operating procedures (SOP) on small (0-100 cows), medium (101-500 cows), and large ( $>500$ cows) dairy farms

\begin{tabular}{lcccc}
\hline & \multicolumn{3}{c}{ Farm size } \\
\cline { 2 - 4 } Statement & Small & \multirow{2}{*}{ Medium } & \multirow{2}{*}{ Large } & \multirow{2}{*}{$P$-value } \\
\hline Existence of SOP & $69(43 / 62)^{\mathrm{a}}$ & $83(105 / 127)^{\mathrm{b}}$ & $93(51 / 55)^{\mathrm{b}}$ & 0.007 \\
Inclusion of employees in creating SOP & $39(24 / 61)^{\mathrm{a}}$ & $47(59 / 126)^{\mathrm{a}}$ & $63(32 / 51)^{\mathrm{b}}$ & 0.021 \\
Availability of SOP for trainees & $15(9 / 60)^{\mathrm{a}}$ & $31(38 / 123)^{\mathrm{b}}$ & $45(22 / 49)^{\mathrm{b}}$ & 0.004 \\
Farms seeking assistance for creating SOP & $55(33 / 60)^{\mathrm{a}}$ & $48(59 / 123)^{\mathrm{a}}$ & $66(33 / 50)^{\mathrm{b}}$ & 0.044 \\
\hline
\end{tabular}

${ }^{\mathrm{a}, \mathrm{b}}$ Within a row, means with different superscripts differ significantly. 
ly, compared with small farms. The existence of written SOP was associated with lower FSCR (without SOP = $52.23 \pm 2.2$; with $\mathrm{SOP}=45.01 \pm 1.8 ; P=0.012)$ but higher annual milk yield (without SOP $=9,477.2 \pm$ $119.7 \mathrm{~kg}$; with $\mathrm{SOP}=9,827.9 \pm 103.8 \mathrm{~kg} ; P=0.028)$.

Another correlation was found between farm size and the inclusion of employees in SOP creation $(P=$ 0.021). Interestingly, employees on large farms were 2.84 times more likely to be involved in the development of SOP compared with employees on small farms $(P=0.007$; Table 3$)$. Seventy percent of the farms did not provide SOP for their trainees. There was a higher probability that written SOP were available on large farms compared with small farms $(P=0.004$; Table 3$)$. Furthermore, large farms were more likely to seek assistance in developing SOP compared with small farms (95\% CI $=0.22-0.81 ; P=0.013$; Table 3). Most of the farmers who sought assistance $(42 \%)$ referred to the veterinarian as their primary advisor. Other sources were feeding consultants (28\%), the local DHIA (12\%), extension experts $(9 \%)$, other farmers $(6 \%)$, and breeding companies (3\%). Sixty-three percent of the respondents stated that they do not check the validity of their SOP on a regular basis. It is noteworthy that on $48 \%$ of the farms employees did not have free access to the SOP at all times.

\section{SOP and Attitude Toward Employment}

Almost all respondents (98\%) wanted to improve certain areas. The majority of the farmers saw the need for improvement in managing fresh cows (49\%), heat detection (47\%), and managing calves (44\%). The question regarding possible benefits of SOP was answered by 179 participants; $86 \%$ considered a consistent work performance to be an obvious benefit, $49 \%$ (87/179) regarded monitoring of work processes as beneficial, and $39 \%(70 / 179)$ saw improvement of animal health as beneficial.

Interestingly, a relationship was found between monitoring work processes as a potential benefit of SOP and the way participants assessed employees who fulfilled work processes differently than what they considered correct $(P=0.030)$. If work monitoring was considered a potential benefit, participants were more likely to state that employees fulfill work processes differently than what they considered correct. Figure 1 shows the overall assessment of the statements.

Sixty-six percent of the participants agreed or strongly agreed with the statement that various employees handled the same tasks differently. Furthermore, farmers who agreed that various employees handled the same tasks differently had a stronger interest in ready-

Table 4. Logistic regression model predicting the probability of having standard operating procedures in different management areas in German dairy herds $(\mathrm{n}=234)$

\begin{tabular}{|c|c|c|c|c|}
\hline Management area & Farm size $^{1}$ & Odds ratio & $95 \%$ CI for odds ratio & $P$-value \\
\hline \multirow[t]{4}{*}{$\overline{\text { Feeding }}$} & & & & $<0.001$ \\
\hline & Small & Referent & & \\
\hline & Medium & 2.45 & $1.29-4.64$ & 0.006 \\
\hline & Large & 6.73 & $2.51-17.99$ & $<0.001$ \\
\hline \multirow[t]{4}{*}{ Milking procedures } & & & & $<0.001$ \\
\hline & Small & Referent & & \\
\hline & Medium & 3.09 & $1.63-5.88$ & 0.001 \\
\hline & Large & 10.00 & $3.52-28.45$ & $<0.001$ \\
\hline \multirow{4}{*}{ Heat detection } & & & & 0.002 \\
\hline & Small & Referent & & \\
\hline & Medium & 2.21 & $1.09-4.50$ & 0.28 \\
\hline & Large & 4.20 & $1.87-9.44$ & 0.001 \\
\hline \multirow[t]{4}{*}{ Fresh cows } & & & & $<0.001$ \\
\hline & Small & Referent & & \\
\hline & Medium & 3.95 & $2.04-7.64$ & $<0.001$ \\
\hline & Large & 4.65 & $2.88-14.45$ & $<0.001$ \\
\hline \multirow[t]{4}{*}{ Calving } & & & & $<0.001$ \\
\hline & Small & Referent & & \\
\hline & Medium & 4.51 & $2.19-9.26$ & $<0.001$ \\
\hline & Large & 9.31 & $3.98-21.81$ & $<0.001$ \\
\hline \multirow[t]{4}{*}{ Calf management } & & & & 0.004 \\
\hline & Small & Referent & & \\
\hline & Medium & 1.94 & $1.05-3.60$ & 0.035 \\
\hline & Large & 3.82 & $1.69-8.60$ & 0.001 \\
\hline \multirow{4}{*}{ Claw trimming } & & & & 0.186 \\
\hline & Small & Referent & & \\
\hline & Medium & 1.39 & $0.72-2.68$ & 0.328 \\
\hline & Large & 2.04 & $0.95-4.37$ & 0.068 \\
\hline
\end{tabular}

${ }^{1}$ Small: 0 to 100 cows; medium: 101 to 500 cows; large: $>500$ cows. 


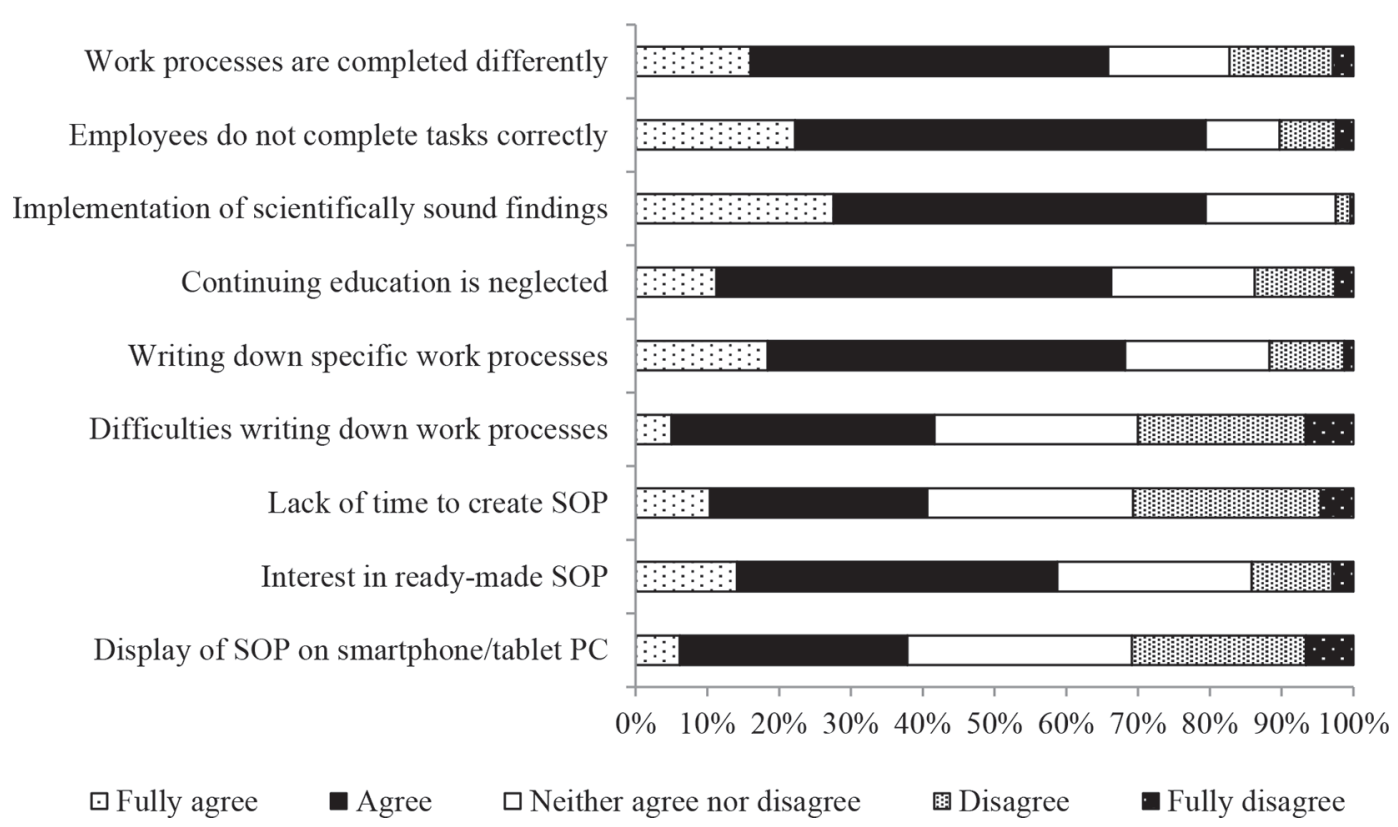

Figure 1. Level of agreement or disagreement with 9 statements regarding generating and implementing standard operating procedures $(\mathrm{SOP} ; \mathrm{n}=241)$.

made $\operatorname{SOP}(P=0.084)$ and were more likely to provide unlimited access to SOP on the farm $(P=0.057)$.

A relationship existed between lack of time for developing SOP and having an interest in using ready-made SOP that could be adapted to the particular farm $(P$ $<0.001)$, although the correlation coefficient was weak $(\mathrm{r}=0.203 ; P=0.002)$. An interest in such ready-made SOP was also slightly positively correlated with farmers having difficulties in creating SOP $(\mathrm{r}=0.186 ; P=$ $0.004)$.

The statement that a farmer lacked time for creating an SOP had a significant effect on the existence of SOP on the farm $(P=0.006)$. Farmers who agreed, neither agreed nor disagreed, or disagreed with lacking time for creating SOP were 2.54 times $(95 \% \mathrm{CI}=0.97-6.66 ; P$ $=0.058), 6.35$ times $(95 \% \mathrm{CI}=2.13-18.88 ; P=0.001)$, and 5.82 times $(95 \% \mathrm{CI}=1.95-17.36 ; P=0.002)$ more likely to have SOP on their farm compared with farmers who fully agreed. There was no effect of farm size on the lack of time for developing SOP $(P=0.596)$, the interest in ready-made $\mathrm{SOP}(P=0.256)$, or the interest in displaying $\mathrm{SOP}$ on a smartphone or tablet $(P=0.190)$.

The power of analysis for calculations concerning the effect of SOP on milk yield, SCC, and FSCR was 0.6369 for the effect of SOP in general on milk yield, 0.7551 for the effect of milking SOP on SCC, and 0.8026 for the effect of milking SOP on milk yield. Furthermore, the statistical power for calculations concerning the effect of farm size on the probability of the existence of SOP for trainees was 0.9515 . Although the power of analysis for the first calculation is low, the other calculations are within the limits set by Cohen (1988) and Prajapati et al. (2010). The chance of error in accepting the null hypothesis differed between 4.9 and $36.3 \%$.

\section{DISCUSSION}

Farm size in our study was categorized based on number of cows as in previous surveys (Kehoe et al., 2007; Heuwieser et al., 2010; Espadamala et al., 2016), and a relationship exists between number of cows and number of employees (USDA, 2008). Globally, the agricultural sector in many countries has been changing toward larger operations and away from small, familyowned businesses (Barkema et al., 2015). The German dairy industry is undergoing this shift as well. There are, however, regional differences. Herd sizes and annual milk yield are higher in eastern regions compared with western and southern regions. Most of the small, family-owned farms in the Southwest stay below the German average herd size of 60 cows and the average milk yield of $7,628 \mathrm{~kg} / \mathrm{yr}$, whereas the herd sizes and milk yields of larger dairy operations in the East are above average (ZMB, 2016). Furthermore, the proportion of nonpermanent employed workers has been increasing over the past years. Interestingly, $90 \%$ of these nonpermanent workers come from countries other than Germany (DBV, 2015). As dairy farms expand, they increasingly rely on nonfamily labor (Bewley et 
al., 2001; Barkema et al., 2015) and a foreign workforce (Susanto et al., 2010), thus leading to more communication challenges (Barkema et al., 2015; Erskine et al., 2015). On those farms, dairy managers have the responsibility of ensuring that employees are performing high-quality work (Stup et al., 2006). It has been described that managers of larger herds place more emphasis on details to improve important herd performance measures (Bewley et al., 2001), which led us to assume that larger farms are more likely to have SOP than small farms. Also, herd managers from large farms may interact with veterinarians and consultants more often. Both observations could have influenced the results.

Standard operating procedures existed on the majority of farms, but, interestingly, they were not written down. Respondents did not see the importance of written SOP for the consistency of work performance. It has been pointed out, however, that meaningful records are essential for implementing corrective measures and adjusting management (Barragan et al., 2016). Another possible explanation is that some managers and producers lack the capacity to address human resource management (Erskine et al., 2015) or struggle with the transition toward it (Reynolds et al., 2013) and therefore consider a verbal instruction or explanation to be an SOP without being aware of the importance of a formal written SOP. Nevertheless, it was more likely for SOP to be written down on large farms than on small farms. The availability of competent labor is often problematic (Winsten et al., 2010), and dairy producers consider its recruitment to be a major problem (Bewley et al., 2001). Whereas work on small farms is completed primarily by family members, large farms need to overcome language barriers and avoid communication problems that are attributable to the higher proportion of foreign workers. To be successful, a high level of management ability is required (Bewley et al., 2001; Winsten et al., 2010), and implementation of SOP becomes an essential management tool (Barragan et al., 2016). As farm size increases, producers spend more time managing employees, allowing them to adjust to the challenges of employee management sooner (Bewley et al., 2001). This explains why in our data set large farms were more likely to provide SOP for their trainees compared with small farms that rely mostly on family workers and often do not have any trainees. Considering the ongoing trend toward larger dairy herds (Bewley et al., 2001), a focus needs to be placed on the implementation of best management practices (LeBlanc et al., 2006; Cummins et al., 2016). A better understanding of the importance of a quality assurance system makes it more likely for large farms to seek assistance compared with small dairy producers.
Most farmers stated that they sought the assistance of a veterinarian. Veterinarians clearly are seen as important advisors on many dairies, as previously stated (Moore et al., 2016).

Human resource management characterizes a set of practices that managers use to ensure quality employee performance (Stup, 2001). To optimize overall performance, different employees need to complete the same tasks similarly, which is encouraged by the implementation of SOP. This is important because dairy cattle thrive on consistency (Maunsell, 2012). Milk quality and quantity are directly affected by employee performance (Stup et al., 2006). This could explain the significantly higher milk yield on farms that had written SOP compared with those that did not. Poor human-animal relationships result in low work comfort and efficiency and are associated with reduced milk production (des Roches Ade et al., 2016). The greater the number of employees working on a farm, the more difficult it is to ensure consistency of work performance. The majority of respondents stated that different employees completed the same tasks differently. Farms with such conditions would particularly benefit from SOP because these prevent variations regardless of the operator and time of operation (Amare, 2012). On large farms, the management is more likely to create SOP together with their employees because the owners, managers, and veterinarians rely on the employees to identify sick cows under variable formal training and supervision (Espadamala et al., 2016). This observation, however, is put into perspective as small farms are often family owned and less likely to hire employees as opposed to medium and large farms. The best practice for developing SOP requires the active involvement of workers (Amare, 2012). However, implementing a quality management system with SOP is time consuming and requires specific know-how. This aspect can explain the observed interest of farmers $(59 \% ; 141 / 240)$ in ready-made SOP.

Interestingly, the biggest challenge for producers after expansion seems to be labor management (Bewley et al., 2001); many herd owners and managers are neither trained nor inclined to serve as an educator (Erskine et al., 2015). Considering this challenge and the evolution of veterinarians from task-oriented providers to advice-oriented consultants (LeBlanc et al., 2006), an opportunity opens for veterinarians to maintain or reestablish an important role on the dairy farm through development and communication of treatment protocols for animal care and well-being (Moore et al., 2016). In addition, in a valid veterinary-client relationship, the veterinarian should provide written treatment protocols and guidelines for commonly occurring and easily recognizable conditions (AABP, 2013). These protocols 
and SOP should be user friendly and easy to understand because they are targeted at diverse employees from different cultural backgrounds. Our data show that veterinarians are an important source of assistance for farmers who create SOP as part of their human resource management. Because effectively writing SOP requires special know-how and training, such expertise should be included in veterinary education.

Interestingly, the SCC was higher on farms that had SOP for milking procedures compared with farms without such SOP. Additionally, SOP were more likely to be written down on farms with a lower FSCR. Furthermore, farms with a lower FSCR were more likely to have SOP for heat detection. We do not assume that higher SCC and lower FSCR are caused by the implementation of SOP. A possible explanation for this result could be the implementation of SOP as a corrective measure to improve workers' performance and productivity on these farms. The study design, however, allows only an insight into the current status of the participating dairies and does not justify making a statement about cause and effect. This finding is in line with the observation that SOP sometimes are used to correct poor performance (Stup et al., 2006) and indicates that farmers are aware of the importance of good farm management for product quality and efficiency. Our data reflect this assumption, as large farms were more likely to have implemented SOP and had higher milk yields. Regardless, the assumption that having written SOP has a positive effect on outcomes of value to a given producer or the industry as a whole needs to be demonstrated.

As in other studies surveying certain management practices related to, for example, reproductive performance, postpartum disorders, or colostrum management (Caraviello et al., 2006; Kehoe et al., 2007; Heuwieser et al., 2010), our study had limitations. Such surveys rely on voluntary responses of the target population (i.e., generally a convenience sample of a certain geographical region). It is difficult to conclude whether the dairies that responded to the survey are representative of all dairies of the given region but reasonable to assume that the farms that responded were more interested in human resource issues than the nonresponding farms. Despite these limitations, surveys have provided important insights into current dairy management practices and experiences in a variety of areas, such as animal health and welfare, facility characteristics, and feeding.

Similar to a recent study on management practices related to bovine respiratory diseases in calves (Love et al., 2016), responses were recruited from several sources. Therefore, a response rate could not be calculated. Considering the large number of questionnaire forms sent out, only a small number of farms participated in the survey. German dairy farmers clearly did not perceive management of work processes to be as important as other areas such as reproductive performance, postpartum disorders, or drying-off practices, for which studies reported response rates of 67,12 , and $49 \%$, respectively. The survey was based on the farmers' voluntary participation and relied on the participants' assessment of the situation on their farm. However, the study did not include any farm visits or personal interviews, which should be part of a follow-up study. The mean herd size in our study was 230 cows, which is greater than demographic data on the German dairy industry (DBV, 2015).

\section{CONCLUSIONS}

The majority of respondents saw a need for improvement of certain management areas and indicated the existence of SOP. The SOP were written down in only $54 \%$ of cases and were available to trainees in $30 \%$ of cases, and both were associated with farm size. Many respondents indicated a lack of time or ability to create written SOP. Further research is warranted to study the efficacy and compliance of ready-made SOP considering the type of training material.

\section{ACKNOWLEDGMENTS}

We thank Rinderallianz GmbH (Woldegk, Germany), Rinderunion Baden-Württemberg (Herbertingen, Germany), and Deutsche Landwirtschaftliche Gesellschaft AgroFood Medien GmbH (Groß-Umstadt, Germany) for their support in conducting this survey. Anne Hesse was sponsored in part by QS, Qualität und Sicherheit GmbH (Bonn, Germany), and Tiergyn e.V. Berlin (Berlin, Germany).

\section{REFERENCES}

AABP (American Association of Bovine Practitioners). 2013. Establishing and Maintaining the Veterinary-Client-Patient Relationship in Bovine Practice. AABP, Auburn, AL.

Almeida, A. M., A. Bassols, E. Bendixen, M. Bhide, F. Ceciliani, S. Cristobal, P. D. Eckersall, K. Hollung, F. Lisacek, G. Mazzucchelli, M. McLaughlin, I. Miller, J. E. Nally, J. Plowman, J. Renaut, P. Rodrigues, P. Roncada, J. Staric, and R. Turk. 2015. Animal board invited review: Advances in proteomics for animal and food sciences. Animal 9:1-17.

Amare, G. 2012. Reviewing the values of a standard operating procedure. Ethiop. J. Health Sci. 22:205-208.

Bánáti, D. 2014. European perspectives of food safety. J. Sci. Food Agric. 94:1941-1946.

Barkema, H. W., M. A. von Keyserlingk, J. P. Kastelic, T. J. Lam, C. Luby, J. P. Roy, S. J. LeBlanc, G. P. Keefe, and D. F. Kelton. 2015. Invited review: Changes in the dairy industry affecting dairy cattle health and welfare. J. Dairy Sci. 98:7426-7445.

Barragan, A. A., J. D. Workman, S. Bas, K. L. Proudfoot, and G. M. Schuenemann. 2016. Assessment of an application for touchscreen 
devices to record calving-related events in dairy herds and monitor personnel performance. J. Dairy Sci. 99:5662-5670.

Bauer, M., S. Riech, I. Brandes, and R. M. Waeschle. 2015. Advantages and disadvantages of different methods for the implementation and the support of standard operating procedures: From PDF files to an app- and web-based SOP management system. Anaesthesist 64:874-883.

Bewley, J., R. W. Palmer, and D. B. Jackson-Smith. 2001. An overview of experiences of Wisconsin dairy farmers who modernized their operations. J. Dairy Sci. 84:717-729.

Caraviello, D. Z., K. A. Weigel, P. M. Fricke, M. C. Wiltbank, M. J. Florent, N. B. Cook, K. V. Nordlund, N. R. Zwald, and C. L. Rawson. 2006. Survey of management practices on reproductive performance of dairy cattle on large US commercial farms. J. Dairy Sci. 89:4723-4735.

Cohen, J. 1988. Statistical Power Analysis for the Behavioral Sciences. 2nd ed. Taylor and Francis, Hillsdale, NJ.

Cummins, C., D. P. Berry, R. Sayers, I. Lorenz, and E. Kennedy. 2016. Questionnaire identifying management practices surrounding calving on spring-calving dairy farms and their associations with herd size and herd expansion. Animal 10:868-877.

DBV (Deutscher Bauernverband V). 2015. Situationsbericht 2015/16. Trends und Fakten zur Landwirtschaft. Accessed Aug. 20, 2016. http://www.situationsbericht.de.

des Roches,, A. B., I. Veissier, X. Boivin, E. Gilot-Fromont, and L. Mounier. 2016. A prospective exploration of farm, farmer, and animal characteristics in human-animal relationships: An epidemiological survey. J. Dairy Sci. 99:5573-5585.

Dohoo, I. R., S. W. Martin, and H. Stryhn. 2009. Veterinary Epidemiologic Research. 2nd ed. University of Prince Edward Island, Charlottetown, PEI, Canada.

Erskine, R. J., R. O. Martinez, and G. A. Contreras. 2015. Cultural lag: A new challenge for mastitis control on dairy farms in the United States. J. Dairy Sci. 98:8240-8244.

Espadamala, A., P. Pallares, A. Lago, and N. Silva-Del-Rio. 2016. Fresh-cow handling practices and methods for identification of health disorders on 45 dairy farms in California. J. Dairy Sci. 99:9319-9333.

Ewerbeck, V. 2014. Standardverfahren in der operativen Orthopädie und Unfallchirurgie. 4, vollständig überarbeitete und erweiterte Auflage. Georg Thieme Verlag, Stuttgart, Germany.

Friesecke, S., A. Schwabe, S. S. Stecher, and P. Abel. 2014. Improvement of enteral nutrition in intensive care unit patients by a nursedriven feeding protocol. Nurs. Crit. Care 19:204-210.

German, R. N., C. E. Thompson, and T. G. Benton. 2016. Relationships among multiple aspects of agriculture's environmental impact and productivity: A meta-analysis to guide sustainable agriculture. Biol. Rev. 92:716-738.

Heuwieser, W., M. Iwersen, J. Gossellin, and M. Drillich. 2010. Short communication: Survey of fresh cow management practices of dairy cattle on small and large commercial farms. J. Dairy Sci. 93:1065-1068.

Kehoe, S. I., B. M. Jayarao, and A. J. Heinrichs. 2007. A survey of bovine colostrum composition and colostrum management practices on Pennsylvania dairy farms. J. Dairy Sci. 90:4108-4116.

Keswani, R. N., R. Yadlapati, K. M. Gleason, J. D. Ciolino, M. Manka, K. J. O'Leary, C. Barnard, and J. E. Pandolfino. 2015. Physician report cards and implementing standards of practice are both significantly associated with improved screening colonoscopy quality. Am. J. Gastroenterol. 110:1134-1139.

Kloth, J. K., R. Neumann, E. von Stillfried, W. Stiller, I. Burkholder, H. U. Kauczor, V. Ewerbeck, and M. A. Weber. 2016. Qualitycontrolled dose-reduction of pelvic X-ray examinations in infants with hip dysplasia. Eur. J. Radiol. 85:233-238.

LeBlanc, S. J., K. D. Lissemore, D. F. Kelton, T. F. Duffield, and K. E. Leslie. 2006. Major advances in disease prevention in dairy cattle. J. Dairy Sci. 89:1267-1279.
Love, W. J., T. W. Lehenbauer, B. M. Karle, L. E. Hulbert, R. J. Anderson, A. L. Van Eenennaam, T. B. Farver, and S. S. Aly. 2016. Survey of management practices related to bovine respiratory disease in preweaned calves on California dairies. J. Dairy Sci. 99:1483-1494.

Manghani, K. 2011. Quality assurance: Importance of systems and standard operating procedures. Perspect. Clin. Res. 2:34-37.

Maunsell, F. 2012. Effective use of standard operating procedures on dairies to improve herd health. Page 43 in Proc. 48th Florida Dairy Production Conference, Gainesville, FL. University of Florida, IFAS Extension, Gainesville.

McCrea, D. 2005. Risk communication related to animal products derived from biotechnology. Rev. Sci. Tech. 24:141-148.

Moore, D. A., W. M. Sischo, S. Kurtz, J. D. Siler, R. V. Pereira, L. D. Warnick, and M. A. Davis. 2016. Improving dairy organizational communication from the veterinarian's perspective: Results of a continuing veterinary medical education pilot program. J. Vet. Med. Educ. 43:33-40.

Pieper, L., M. G. Doherr, and W. Heuwieser. 2016. Consumers' attitudes about milk quality and fertilization methods in dairy cows in Germany. J. Dairy Sci. 99:3162-3170.

Prajapati, B., M. Dunne, and R. Armstrong. 2010. Sample size estimation and statistical power analyses. Optom. Today 50:16.

QuestBack GmbH. 2016. Online survey software. Accessed Feb. 18, 2016. http://my.unipark.com/.

Reynolds, S. J., D. Douphrate, R. Hagevoort, B. Brazile, and K. Root. 2013. Managing worker safety, productivity, and regulatory issues. Page 54 in Proc. Western Dairy Management Conference, Reno, NV. Western Dairy Management Conference, Reno, NV.

SOPHIA. 2014. SOP management system. Accessed Mar. 15, 2016. https://sop.management.

Streyl, D., C. Sauter-Louis, A. Braunert, D. Lange, F. Weber, and H. Zerbe. 2011. Establishment of a standard operating procedure for predicting the time of calving in cattle. J. Vet. Sci. 12:177-185.

Stup, R. 2001. Standard operating procedures: A writing guide. Accessed Feb. 18, 2016. http://extension.psu.edu/animals/dairy/hr/ tools-for-dairy-employee-supervisors/ud011.

Stup, R. E., J. Hyde, and L. A. Holden. 2006. Relationships between selected human resource management practices and dairy farm performance. J. Dairy Sci. 89:1116-1120.

Susanto, D., C. P. Rosson, D. P. Anderson, and F. J. Adcock. 2010. Immigration policy, foreign agricultural labor, and exit intentions in the United States dairy industry. J. Dairy Sci. 93:1774-1781.

USDA. 2008. Dairy 2007. Part III: Reference of dairy cattle health and management practices in the United States. USDA. Animal and Plant Health Inspection Service, Veterinary Services, and National Animal Health Monitoring System, Fort Collins, CO.

von Keyserlingk, M. A. G., and M. J. Hotzel. 2015. The ticking clock: Addressing farm animal welfare in emerging countries. J Agric. Environ. Ethics 28:179-195.

Windhaus, A., D. Meemken, T. Blaha, and G. Klein. 2007. Results of the evaluation of food chain information for a risk-oriented meat inspection. Dtsch. Tierarztl. Wochenschr. 114:305-308.

Winsten, J. R., C. D. Kerchner, A. Richardson, A. Lichau, and J. M. Hyman. 2010. Trends in the Northeast dairy industry: Large-scale modern confinement feeding and management-intensive grazing. J. Dairy Sci. 93:1759-1769.

Yu, F. J., S. L. Hwang, and Y. H. Huang. 1999. Task analysis for industrial work process from aspects of human reliability and system safety. Risk Anal. 19:401-415.

ZMB (Zentrale Milchmarkt Berichterstattung GmbH). 2016. Milchindustrie-Verband e.V. 2016. Beilage zum Geschäftsbericht 2015/16, Zahlen-Daten-Fakten. ZMB, Berlin, Germany. 